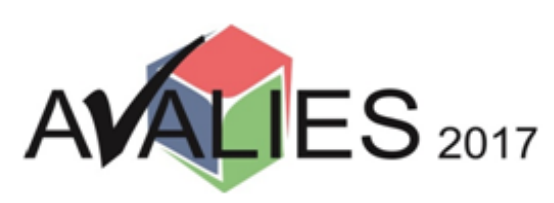

$3^{\circ}$ Simpósio Avaliação da Educação Superior

05 e 06 de setembro de 2017

Florianópolis - SC - Brasil

ISBN: $978-85-68618-04-2$

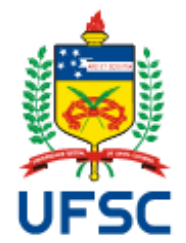

\title{
DA INSTITUIÇÃO AO ARTIGO: CARACTERÍSTICAS E TENDÊNCIAS SOB O MOTE DA AVALIAÇÃO
}

\author{
Eduardo Francisco Fernandes \\ Universidade Federal de Santa Catarina \\ e.fernandes.adm@gmail.com \\ Carla Santana \\ Universidade Federal de Santa Catarina \\ carla.ufsc@gmail.com
}

\section{RESUMO}

Frente à importância do tema e foco deste evento, buscou-se neste artigo apresentar características e tendências do processo de avaliação no sistema nacional de educação com ênfase nos níveis de graduação e pós-graduação, por meio de uma pesquisa descritiva de cunho qualitativa. O presente estudo atinge seu objetivo em grande parte na própria fundamentação teórica, no tocante a caracterização do ensino superior. Na etapa de resultados, focou-se em apresentar os pontos principais por meio da ilustração do processo de avaliação em nível de graduação e pós-graduação. Em síntese, observa-se que o processo de avaliação é fundamental, dentre outras questões, para a manutenção e garantia de um ensino superior de efetiva qualidade. $\mathrm{O}$ artigo contempla ainda, possíveis tendências de alteração dos processos de avaliação no ensino superior. No que diz respeito à pós-graduação, diversas alterações já foram executadas e outras estão previstas para os próximos anos. Além disso, a oferta de Doutorado Profissional stricto sensu, desperta a atenção para novas modificações no sistema de avaliação, a fim de abarcar esta demanda e conferir os devidos patamares de qualidade a esta nova modalidade.

Palavras chave: Processo de Avaliação, Graduação, Pós-graduação, Características e Tendências. 


\section{INTRODUÇÃO}

Diante da pressão gerada por um ambiente cada vez mais competitivo aumenta a preocupação das Instituições de Ensino Superior (IES) com a necessidade de bons resultados e desempenho. Além de receber pressão por parte do governo na avaliação do sistema de ensino superior, também é cobrada pela própria sociedade, a qual requisita excelência na qualidade de ensino e atuação. Para isso, torna-se indispensável recorrer a instrumentos para avaliação das IES, principalmente em relação ao desempenho de estudantes, cursos e programas em nível de graduação e pós-graduação. Além de se consubstanciar em elemento fundamental para tornar transparente a prestação de contas à sociedade, é um instrumento para planejamento da gestão e desenvolvimento da educação superior (PASCUCI, et al. 2016).

Destarte, a avaliação institucional pode ser compreendida como "um processo que tem por objetivo contribuir para a elevação do nível de qualidade da educação superior" (PINTO, 2016 , p. 90). E neste processo a figura do avaliador é extremamente importante na contribuição com a tomada de decisão por meio do fornecimento de informações e análises que aumentam o conhecimento dos problemas educacionais. Ressalta-se ainda que a avaliação e os avaliadores necessitam estar intrinsecamente ligados por objetivos, conceitos, signos e valores, a fim de tornar o processo efetivo e minimizar possíveis resistências (LAVOR; ANDRIOLA; LIMA, 2015).

Neste contexto, este trabalho tem por objetivo apresentar características e tendências do processo de avaliação no sistema nacional de educação com ênfase nos níveis de graduação e pós-graduação. Para isso, discorre-se sobre o tema buscando evidenciar informações no que diz respeito ao processo de avaliação em IES, sua importância, aplicabilidade em distintos contextos, operacionalização da avaliação institucional, auto avaliação, avaliação externa, avaliação discente e docente, avaliação de curso e programas. E nesse ínterim, também retratar o envolvimento de distintos agentes do campo, vinculados ao processo de avaliação.

\section{FUNDAMENTAÇÃO TEÓRICA}

\subsection{AVALIAÇÃO DA EDUCAÇÃO SUPERIOR}

A avaliação é um processo que se permite realizar em distintas situações, segmentos, processos e atividades, cabendo adaptá-la a peculiaridade de cada contexto. Nesse sentido, no que tange o ensino superior é possível citar, dentre outras, a avaliação institucional, avaliação discente, docente, de curso e programas. Para Dias e Ketzer (2007, p. 219) "a avaliação institucional deixou de ser atividade opcional nos processos educacionais contemporâneos, para se transformar em componente intrínseco e necessariamente rotineiro de toda a vida acadêmica", contribuindo para o contínuo aperfeiçoamento do desempenho acadêmico.

No tocante a auto avaliação institucional, a organização se dá sob a perspectiva da identidade institucional (missão, valores éticos e objetivos projetados no Plano de Desenvolvimento Institucional - PDI e Projeto Pedagógico Institucional - PPI); globalidade, considerando as relações internas e externas, com foco inicial nas unidades de ensino, pesquisa e extensão; participação de todos os segmentos da IES; sistemática de comparabilidade, para comparação e relação de dimensões objetivas e subjetivas da instituição; continuidade da avaliação; e sistematização, ou seja, estruturada de forma a permitir uma visualização crítica e singular do processo. Cabe evidenciar que uma auto avaliação, precisa ser complementada com a avaliação externa à instituição. Com a articulação entre ambas, obtêm-se subsídios de relevada importância para a discussão com a 
comunidade acadêmica, ensejando, quando pertinente, a revisão de ações, processos e de forma geral, o plano de desenvolvimento, projeto pedagógico institucional e projeto pedagógico do curso, bem como o aprimoramento das relações com a sociedade (DIAS; KETZER, 2007).

Sobre a avaliação de cursos, um ponto importante para se avaliar é a sua coordenação, pelo fato de ser o responsável pela administração da área pedagógica e a gestão das demandas do curso, devendo articular políticas específicas que garantam as condições necessárias para execução das atividades acadêmicas, bem como facilitar a interação entre os alunos e a alta administração da IES (LAVOR; ANDRIOLA; LIMA, 2015).

A cerca da avaliação discente, ressalta-se que o tema tem avançado e ganhado forte importância na gestão universitária em virtude das profundas reformulações da educação superior no Brasil e no mundo e por se consolidar num objeto de constante debate. Contudo, sem afetar o modo de operacionalizar o processo de avaliação do aprendizado discente. A avaliação deve ser compreendida num contexto amplo, ou seja, como atitude de responsabilidade da instituição, docentes e discentes, de forma que incentive a reflexão desses agentes sobre os instrumentos de ensino e aprendizagem (DIAS; KETZER, 2007).

No âmbito da graduação, as primeiras iniciativas de avaliação no país tiveram início nos anos 80, constituindo-se como pilar principal da agenda política educacional nos anos 90 . Os anos de 1993 e 1994 foram históricos no que diz respeito à avaliação, com a criação de propostas concretas de ação. Sob a coordenação da Associação Nacional dos Dirigentes das Instituições Federais de Ensino Superior (ANDIFES), diversas instituições elaboram um projeto de Programa Nacional de Avaliação requisitado pelo Ministério da Educação (MEC). Em 1993, ocorreu a criação do Programa de Avaliação Institucional das Universidades Brasileiras (PAIUB) e a adoção do documento básico de avaliação das universidades, ocorrendo à avaliação do PAIUB em 1994. Em 1995, por meio da Lei n. 9.131, encerrou-se o efetivo apoio ao PAIUB e, por consequência, a criação pelo MEC, de um novo mecanismo de avaliação para os concluintes de cursos da graduação: o Exame Nacional de Cursos, também conhecido como Provão, destinado aos concluintes de cursos de graduação (PINTO, 2016).

Em 03 de dezembro de 1997 o Conselho Nacional de Educação (CNE) aprovou o Parecer n. 776/97 determinando a orientação para as diretrizes curriculares dos cursos de graduação, bem como de avaliações periódicas com instrumentos variados. Em 2003, uma proposta de avaliação foi apresentada pela Comissão Especial de Avaliação - CEA, nomeada: Bases para uma Proposta de Avaliação da Educação Superior. Esta foi a base que ensejou a construção do atual sistema de avaliação o Sistema Nacional de Avaliação da Educação Superior (SINAES) instituído pela Lei no 10.861/2004 (PINTO, 2016).

Nesta mesma lei, foi instituída a Comissão Nacional de Avaliação da Educação Superior (CONAES), órgão colegiado de coordenação e supervisão do SINAES. Cabe relatar que o processo de avaliação do SINAES é acompanhado pela Comissão Técnica de Acompanhamento da Avaliação (CTAA), que atua no acompanhamento dos processos de avaliação institucional externa e de avaliação dos cursos de graduação das IES do SINAES, além de acompanhar também os processos do Sistema de Acreditação Regional de Cursos de Graduação do MERCOSUL (BRASIL, 2004).

Com foco na caracterização do SINAES, tem por finalidades a melhoria da qualidade da educação superior por meio da: integração, participação, promoção de valores democráticos, respeito à diversidade, busca da autonomia, afirmação da identidade e dimensão formativa. Apresenta uma concepção de avaliação que se constitui em instrumento de política educacional, voltada para a construção e consolidação da qualidade, da participação e da ética na educação superior. Além disso, é regido sob os seguintes princípios: educação como um direito social e dever do Estado; reconhecimento dos valores sociais historicamente determinados; preocupação com a prática social e com objetivos educativos; 
respeito à identidade e às diversidades institucionais; visão e preservação da globalidade; e atenção à perspectiva de processo contínuo (BRASIL, 2004).

Já em relação à sistemática de avaliação estabelecida pelo SINAES, de acordo com Pinto (2016), tem como base três processos:

a) Avaliação das Instituições de Educação Superior - AVALIES;

b) Avaliação dos Cursos de Graduação - ACG;

c) Avaliação do Desempenho dos Estudantes - ENADE.

Além disso, o SINAES funciona a partir de uma série de instrumentos que são produzidos em distintas instâncias e por diferentes meios, tais como:

(i) avaliação interna a partir da Comissão Própria de Avaliação (CPA) e, no caso das universidades, também é necessário um Plano de Desenvolvimento Institucional (PDI) com planejamento no prazo de cinco anos; (ii) avaliação externa, que constitui um grupo composto pelo próprio corpo acadêmico fazendo a avaliação entre pares (a partir de certos parâmetros definidos pelo MEC); (iii) o CES, a partir de levantamentos realizados anualmente pelo INEP; e (iv) a aplicação do Exame Nacional de Desempenho dos Estudantes (ENADE) que, diferentemente do antigo Provão, avalia aspectos voltados ao conhecimento geral atingindo estudantes na entrada do curso (com $7 \%$ a $22 \%$ da grade curricular concluída) e ao fim do curso (com $80 \%$ ou mais da grade concluída) de forma a produzir um cenário que faça a comparação na produção da formação, mais do que avaliar o conteúdo adquirido (DINALLI; ZAMBELLO, 2017, p. 369-370).

Consoante Pinto (2016) as avaliações proporcionam importantes subsídios que consubstanciam referencial básico dos processos de regulação e supervisão da educação superior, compreendendo o credenciamento e a renovação de credenciamento de IES, a autorização, o reconhecimento e a renovação de reconhecimento de cursos de graduação.

Além disso, o sistema de avaliação implantado pelo SINAES organizou um instrumento matricial com cinco eixos, contemplando nestes, as dez dimensões referenciadas no marco legal do SINAES. De acordo com Scorsoline $(2015$, p. 77) os eixos são assim constituídos:

1 - Planejamento e Avaliação Institucional: considera a dimensão 8 do SINAES (Planejamento e Avaliação);

2 - Desenvolvimento Institucional: contempla as dimensões 1 (Missão e o Plano de Desenvolvimento Institucional) e 3 (Responsabilidade Social da Instituição) do SINAES;

3- Políticas Acadêmicas: abrange as dimensões 2 (Políticas para o Ensino, Pesquisa e Extensão), 4 (Comunicação com a Sociedade) e 9 (Políticas de Atendimento aos Discentes) do SINAES;

4 - Políticas de Gestão: compreende as dimensões 5 (Políticas de Pessoal), 6 (Organização e Gestão da Instituição) e 10 (Sustentabilidade Financeira) do SINAES;

5 - Infraestrutura Física: contempla a dimensão 7 (Infraestrutura Física) do SINAES.

Interessante ainda fazer uma breve ilustração sobre os indicadores de qualidade calculados pelo Instituto Nacional de Estudos e Pesquisas Educacionais Anísio Teixeira (INEP) como parâmetros de monitoramento da avaliação do nível de graduação. De acordo com o INEP (2017), atualmente são quatro indicadores calculados com base nos resultados do ENADE e demais insumos constantes das bases de dados do MEC: 
a) Conceito ENADE: mensura a qualidade dos cursos em relação aos conteúdos programáticos, bem como suas habilidades e permite calcular os demais indicadores;

b) Diferença entre os desempenhos Observado e Esperado (IDD): afere o valor agregado pelo curso ao desenvolvimento dos estudantes concluintes;

c) Conceito Preliminar de Curso (CPC): Regulamenta a aplicação do conceito preliminar de cursos superiores, para fins dos processos de renovação de reconhecimento respectivos, no âmbito do ciclo avaliativo do SINAES;

d) Índice Geral de Cursos Avaliados da Instituição (IGC): consolida informações relativas aos cursos superiores constantes dos cadastros, censo e avaliações oficiais disponíveis no INEP e na Coordenação de Aperfeiçoamento de Pessoal de Nível Superior (CAPES).

Por fim, oportuno evidenciar a respeito do processo de regulação e supervisão de IES públicas e privadas pertencentes ao Sistema Federal de Educação Superior Brasileiro. Inicialmente sob incumbência da Secretaria de Educação Superior (SESu), passou a ser realizado pela Secretaria de Regulação e Supervisão da Educação Superior (SERES), unidade do MEC criada em 17 de abril de 2011 pelo Decreto n. 7.480/2011, tendo como objetivo ser indutora da qualidade por meio de ações de regulação e supervisão de instituições e cursos de educação superior. Não obstante essa nova estrutura criada, um ano após, surge o Projeto de Lei n. 4.372/2012 na Câmara dos Deputados, que propõe a criação de uma autarquia federal com atribuições de avaliar e regular a educação superior no Brasil, o INSAES - Instituto Nacional de Supervisão e Avaliação da Educação Superior, ainda em procedimentos na câmara. Salienta-se que em relação às instituições estaduais e municipais de educação superior, a regulação fica a cargo dos sistemas estaduais de ensino (SCORSOLINE, 2015).

Já com enfoque em nível de pós-graduação, a avaliação foi uma consequência da necessidade da CAPES em determinar quem seriam os beneficiários de apoio financeiro ou sobre a recusa de propostas. Para isso a CAPES concentrou sua avaliação na produção científica dos pesquisadores dos programas (BALBACHEVSKY, 2005). A institucionalização do processo de avaliação culminou em uma realidade bem sucedida de um sistema de ensino reconhecido nacional e internacionalmente por sua qualidade. Dessa maneira, ensejou o desenvolvimento de medidas para manutenção desta qualidade, com intuito não só de manter, mas de aprimoramento constante (CURY, 2004).

Desde 1976 há, de forma sistematizada, avaliação da pós-graduação no Brasil. Mas especificamente a partir da Lei n. 5.540/1968 no artigo 24 já se plantava a semente da avaliação no sistema da pós-graduação e, por sua vez, o primeiro passo da avaliação no contexto nacional. No referido artigo, constava que o extinto Conselho Federal de Educação (CFE) conceituaria os cursos de pós-graduação e baixaria normas gerais para sua organização. Foi, portanto, a pós-graduação a primeira a estabelecer a necessidade de avaliação, classificação e rankeamento (DINALLI; ZAMBELLO, 2017).

A CAPES é a responsável pela qualidade do ensino da pós-graduação no país e desempenha papel fundamental na expansão e consolidação da pós-graduação stricto sensu em nível nacional, bem como a representação e alcance de reconhecimento em nível internacional (BRASIL, 2008). Nas últimas décadas dois sistemas de avaliação foram criados. No período de 1976-1997, vigorou a escala conceitual alfabética de A até E, sendo considerados cursos de padrão internacional aqueles contemplados com o conceito A. Em 1998, passou a vigorar a escala numérica de 1 a 7, considerados de nível internacional programas 6 e 7. Para assegurar a validação desta métrica, a Capes promove avaliações periódicas destes programas com comitês internacionais (STEINER, 2005).

De acordo com Lievore et al. (2017) de forma estratégica, a pós-graduação stricto sensu, atua no desenvolvimento científico do país e é marcada por um rigoroso sistema de 
avaliação e reconhecimento dos seus Programas de Pós-Graduação (PPG). O sistema de avaliação pode ser dividido em dois processos distintos que se referem à entrada e à permanência dos cursos de mestrado profissional, mestrado acadêmico e doutorado no SNPG.

Ressalta-se ainda que ambos os processos são conduzidos pelos seguintes fundamentos (BRASIL, 2014):

a) Reconhecimento e confiabilidade fundados na qualidade assegurada pela análise dos pares, oriundos das diferentes áreas do conhecimento e reconhecidos por sua reputação intelectual;

b) Critérios debatidos e atualizados pela comunidade acadêmico-científica a cada período avaliativo;

c) Transparência, com ampla divulgação das decisões, ações e resultados.

No tocante a entrada no SNPG, a inclusão da IES se dá a partir do momento que um curso é recomendado pela CAPES e reconhecido pelo CNE/MEC. Consequentemente adquire a obrigatoriedade de enviar informações a CAPES, relacionadas a toda sua atividade acadêmica e de pesquisa. Dentre outros, devem ser reportados dados de infraestrutura física, formação e atividades de docentes, matrícula e titulação de alunos, disciplinas oferecidas, projetos de pesquisa desenvolvidos, produção bibliográfica em termos de artigos científicos, livros, dissertações e teses defendidas, produção técnica e tecnológica. Essas informações são enviadas de forma contínua e online por meio de um sistema denominado Coleta de Dados.

No que diz respeito a avaliação de permanência, atualmente é realizada em 49 áreas, seguindo uma sistemática e conjunto de quesitos básicos estabelecidos no Conselho Técnico Científico da Educação Superior (CTC-ES). Visando otimizar o processo de avaliação, estas áreas são aglomeradas por critério de afinidade em dois níveis (BRASIL, 2014):

Colégios: O qual se divide em: 1) Ciências da Vida; 2) Ciências Exatas, Tecnológicas e Multidisciplinar; 3) Humanidades.

Grandes Áreas: O qual se divide em: 1) Ciências Agrárias; 2) Ciências Biológicas; 3) Ciências da Saúde; 4) Ciências Exatas e da Terra; 5) Engenharias; 6) Multidisciplinar; 7) Ciências Humanas; 8) Ciências Sociais Aplicadas; 9) Linguística, Letras e Artes.

Vale ressaltar que as informações preenchidas anualmente pelos programas e enviadas a Capes por meio do Coleta de Dados possibilitam a confecção dos Cadernos de Indicadores. Estes se consubstanciam nos relatórios utilizados no processo de avaliação. Atualmente são compostos por 11 documentos, apresentados no quadro 01(BRASIL, 2014).

Quadro 01 - Documentos de apoio à avaliação oriundos dos Cadernos de Indicadores.

\begin{tabular}{|l|l|l|}
\hline PR - Programa* & TE - Teses e Dissertações & PB - Produção Bibliográfica \\
\hline PT - Produção Técnica & PA - Produção Artística & CD - Corpo Docente, Vinculo Formação \\
\hline DI - Disciplinas & LP - Linhas de Pesquisa & PP - Projetos de Pesquisa \\
\hline PO - Proposta do Programa & DA - Docente Atuação & DP - Docente Produção \\
\hline
\end{tabular}

* O Caderno PR - não faz mais parte dos documentos disponíveis a partir de 2007, em função da nova escala do Qualis. Fonte: Portal CAPES. (BRASIL, 2014).

Além dos Cadernos de Indicadores a CAPES utiliza os Documentos de Área como referenciais de avaliação. Neles estão descritos o estado atual, as características e as perspectivas, assim como os quesitos considerados prioritários na avaliação dos programas de pós-graduação. Em conjunto com as Fichas de Avaliação e os Relatórios de Avaliação, os 
Documentos de Área constituem o trinômio que expressa os processos e os resultados da Avaliação Trienal (LIEVORE et al. 2017).

$\mathrm{Na}$ figura 01 é possível observar o fluxograma do processo realizado para desenvolvimento da avaliação trienal e, mais recentemente, a avaliação quadrienal.

Figura 01 - Fluxograma do processo de avaliação trienal e quadrienal realizada pela CAPES.

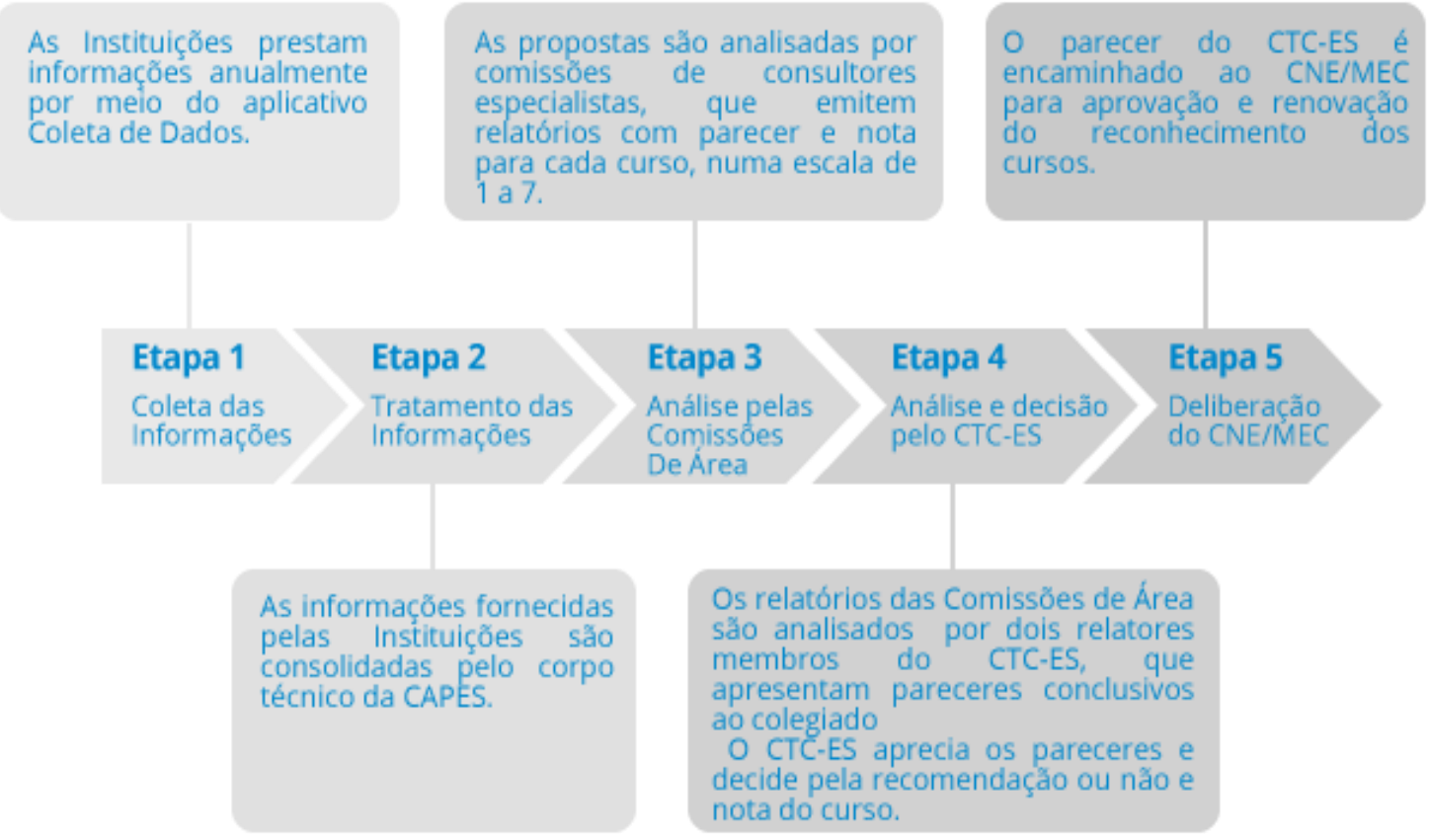

Fonte: Portal CAPES. Sobre a Trienal e Quadrienal (BRASIL, 2014).

A avaliação trienal e quadrienal dos Programas de Pós-Graduação stricto sensu visa com seus resultados (LIEVORE et al., 2017):

a) contribuir para a garantia da qualidade da pós-graduação brasileira: efetivada na identificação dos programas que atendam ao padrão mínimo de qualidade;

b) retratar a situação da pós-graduação brasileira no triênio/quadriênio;

c) contribuir para o desenvolvimento de cada programa e área em particular e da pósgraduação nacional: fornecendo a cada programa avaliado as apreciações criteriosas sobre os pontos fortes e fracos de seu desempenho;

d) fornecer subsídios para a definição de planos e programas de desenvolvimento e de investimentos no Sistema Nacional de Pós-Graduação- SNPG.

No que tange a classificação da produção intelectual, a Capes criou o QualisPeriódicos, que se trata de um sistema usado para classificar a produção científica dos programas de pós-graduação no que se refere aos artigos publicados em periódicos científicos. Ressalta-se que a estratificação da qualidade dessa produção é realizada de forma indireta, ou seja, o Qualis afere a qualidade dos artigos e de outros tipos de produção, a partir da análise da qualidade dos periódicos científicos. A classificação de periódicos é realizada pelas áreas de avaliação e são atualizadas anualmente. Os estratos indicativos da qualidade são: A1, o mais elevado; A2; B1; B2; B3; B4; B5; C - com peso zero. O aplicativo que permite a classificação e consulta ao Qualis das áreas, bem como a divulgação dos critérios utilizados para a classificação de periódicos é o WebQualis (BARATA, 2016). 
Para uma compreensão de forma prática sobre o processo de avaliação vigente na pósgraduação, e também ampliar o amparo no alcance do objetivo deste trabalho, torna-se oportuno uma breve apresentação com foco numa área específica, cuja representação será feita na área de administração por representar as origens de pesquisa e formação dos autores deste trabalho. Nesse sentido, com fulcro no documento de área da avaliação quadrienal para os cursos de Administração Pública e de Empresas, Ciências Contábeis e Turismo, verifica-se que a avaliação ocorre com base em cinco quesitos: Proposta de Programa, Corpo Docente, Corpo Discente, Teses e Dissertações, Produção Intelectual e Inserção Social. Cada quesito é subdividido em itens de avaliação representados pela ficha de avaliação. Os quesitos são definidos pelo CTC-ES e os itens são os mesmos, na grande maioria das áreas, para todas as áreas de avaliação. Ressalta-se que cada modalidade tem uma ficha de avaliação específica, dividindo-se em três tipos: Acadêmicos, Profissionais e Profissionais em Rede Nacional. Já os resultados da avaliação são apresentados de duas formas: um relatório para cada programa e o Relatório da Quadrienal, que é uma síntese da avaliação (BRASIL, 2016).

Com relação à atribuição dos conceitos CAPES, as notas 6 e 7 se baliza nos dados de inserção internacional em composição com dados que evidenciem a liderança do programa no ambiente nacional. Àqueles que atingem nota 5, precisam apresentar os seguintes elementos qualificadores para a candidatura às notas 6 e 7: NDP estável; produção científica em periódicos com fator de impacto ou livros classificados pela área como L4; histórico consolidado na formação de doutores; fluxo regular recente de formação de doutores; distribuição adequada entre os docentes das atividades de cooperação com grupos atuando fora do Brasil; produção científica; formação de alunos e de liderança acadêmica, indicando que o programa não depende da contribuição de um ou poucos docentes. Referente à liderança do programa em âmbito nacional, utilizam-se indicadores já determinados, vinculados a aspectos como: egressos, corpo discente e docente, projetos de pesquisa, dentre outros.

Após análise da liderança nacional, é avaliado o grau de inserção internacional do programa, como forma de avaliar seu grau de equivalência aos centros localizados no exterior em termos da qualidade da formação discente. A avaliação ocorre por meio de indicadores de reconhecimento de qualidade científica e de mobilidade/infraestrutura para a mobilidade. Existem indicadores previamente definidos, mas é possível que os programas apresentem novos aspectos relevantes, que não são apontados. O grau de internacionalização dos programas considerará o perfil dos parceiros internacionais nas ações de cooperação e de mobilidade, identificando se tratam de instituições de referência de qualidade mundial ou instituições de relevância e impacto restrito à região de sua atuação. A área utilizará os dados informados pelos programas na plataforma Sucupira, site e também informações do SciVal (BRASIL, 2016).

Cabe também ilustrar brevemente sobre os desafios enfrentados no sistema nacional de avaliação. Nesse sentido, observa-se que não se aborda no processo de avaliação as IES com fins lucrativos de forma específica, sendo aplicado uniformemente a todas as ofertas de ensino superior. Outro ponto sob este aspecto é que o processo de avaliação governamental foca no desempenho de alunos em conclusão de curso, ao invés do corpo discente como um todo. Isso é um problema visto que muitos dos alunos de instituições com fins lucrativos nunca se graduam em consequência de ações de evasão. Destarte, sua omissão no processo de avaliação torna mais difícil detectar deficiências (KNOBEL; VERHINE, 2017).

Os autores ainda complementam que a maioria dos alunos matriculados em IES com fins lucrativos participantes de programas de acesso e inclusão estão inscritos em programas de baixo custo nos campos do Direito, Pedagogia, Administração e Humanas. Estes programas de graduação favorecem salas de aula maiores, baixos salários do corpo docente, expectativas acadêmicas reduzidas e ausência de políticas para minimizar as taxas de evasão. 
A qualidade destes programas é ainda mais prejudicada pelo crescimento excessivamente rápido e inchaço da estrutura sistêmica do ensino superior, que supera os esforços governamentais para manter padrões mínimos de qualidade na avaliação de programas, cursos e instituições (KNOBEL; VERHINE, 2017).

A despeito dessas especificidades, para Alcadipani (2011, p. 1175) muitos professores almejam estar na pós-graduação apenas pelo prestígio, consequentemente, desviam-se da finalidade principal do ensino aos discentes para cuidar de seus afazeres pessoais na forma de ensino aos executivos de consultorias. Complementa ainda que "muitos dos empresários da educação no Brasil, caso das universidades privadas, querem ganhar dinheiro à custa da péssima formação de alunos e da exploração de professores. Por isso, faz sentido que processos de avaliação sejam realizados pelo governo federal para garantir o mínimo de qualidade dos cursos".

Há também autores indicando que a exigência da CAPES não recaiu igualmente em toda a pós-graduação conferindo aos programas de conceito 6 e 7 uma importância maior ao quesito de produção científica (HORTA, 2002). "A avaliação da educação superior é polêmica tanto no âmbito da graduação quanto no da pós-graduação. Isso porque diferentes são os critérios utilizados -e que nem sempre são consensuais na comunidade acadêmicacomo também o são os recursos disponibilizados para a realização da avaliação" (DINALLI; ZAMBELLO, 2017, p. 363).

Ou ainda sobre o Sistema Qualis, o qual possui classificação absoluta e passa por revisão permanente. Este é um ponto que gera problema, pois uma vez realizada a atualização e chancelada a nova classificação de periódicos, por exemplo, não é possível realizar correções até $\mathrm{o}$ ano seguinte. Consequentemente, muitas reclamações surgem de coordenadores de programas e de editores científicos, interpretando que foram utilizados dados antigos, contudo se trata de uma falha de processamento de dados, cujo erro é corrigido manualmente (BARATA, 2016). Reclamações estas não somente a falhas processuais, mas também vinculadas a diretrizes no que tangem a mudança de critérios de avaliação. Implantando novo Qualis, consequentemente, incorre-se na quebra de pontuação científica de pesquisadores, com eventuais reflexos nos conceitos dos Programas de Pós-graduação (CRESPI et al. 2017).

Outro ponto de vista é a produção de artigos para atender as metas exigidas no sistema de pontuação. Contudo, produção esta não vinculada ao mote do produtivismo de artigos, mas no que diz respeito à transferência da produção de artigos aos discentes e posterior publicação como forma de avaliação final da disciplina. Essa situação “(...) nos parece ser muito mais uma preocupação do docente (que adota essa prática) com a sua própria avaliação diante do programa de pós-graduação ao qual está vinculado (credenciamento e descredenciamento) - e consequentemente da CAPES -, do que uma estratégia avaliativa educativa para os discentes" (BISPO; COSTA, 2016, p.1006).

A própria CAPES reconhece algumas limitações e busca meios de solucionar esses óbices. Ao longo dos anos, o taylorismo intelectual e o imperativo do publish ou perish invadiram todas as áreas e isso refletiu na avaliação, com o predomínio da quantidade sobre a qualidade. Além disso, as áreas profissionais e aplicadas continuam sendo avaliadas a partir de parâmetros das áreas básicas e acadêmicas, prevalecendo o paper e o livro sobre as criações e os inventos. Por fim, a periodicidade da avaliação é excessivamente curta para as necessidades dos programas. Em que pesem as opiniões de que o sistema de pós-graduação e o de avaliação que o acompanha são uma experiência exitosa, é necessário introduzir corretores de rota no conjunto, em atenção à sua complexidade, à sua maturidade e à sua dinâmica interna, com vistas ao plano decenal 2011-2020 (BRASIL, 2010).

Não são poucas nem de pouca monta as consequências do processo de avaliação realizado pela CAPES. Torna-se importante retomar um velho tema: avaliar a avaliação, a fim 
de manter a manutenção constante do sistema e buscar novos formatos que avancem para além dos resultados conseguidos e superem os limites do modelo em curso (KUENZER; MORAES, 2005). Para participar e usufruir das vantagens criadas pela nova economia mundial do conhecimento é fundamental que a pós-graduação e, em especial sua metodologia de avaliação, não entrem num marasmo, mas sim, mantenham a cultura e habilidade de adaptação e auto reforma (BALBACHEVSKY, 2005). Contudo, de acordo com Dinalli e Zambello (2017), percebe-se que a CAPES já vem agindo, neste desiderato, a fundação busca constantemente aprimorar seus métodos de avaliação, sendo possível citar a elaboração de documentos importantes para isso, por exemplo, o Plano Nacional da Pós-Graduação - PNPG.

\section{METODOLOGIA}

A respeito do tipo de estudo, uma pesquisa pode ser classificada quanto aos fins e meios (VERGARA, 2013). Esta pesquisa se caracteriza como descritiva, pelo fato de levantar e expor características do processo de avaliação no sistema de ensino superior brasileiro. No que tange os meios, classifica-se como pesquisa bibliográfica com o uso de referencial teórico já publicado em livros, artigos, legislação, além do uso de dados de portais eletrônicos de instituições reconhecidas e confiáveis.

No tocante a análise e interpretação dos dados, esta mesma autora demonstra que podem ser tratados de forma quantitativa, com suporte de procedimentos estatísticos ou qualitativa por meio de codificação e apresentação dos dados de maneira estruturada. Nessa perspectiva, a análise dos dados ocorrerá de forma qualitativa por meio de seleção, categorização e apresentação em quadro e diretamente no corpo de texto.

Por fim, importante ilustrar no que tange à limitação da pesquisa. De acordo com Vergara (2013) este campo tem a função de evidenciar até onde vai o estudo, a fim de se antecipar às críticas do leitor. Portanto, destaca-se que o estudo abrange a caracterização de como ocorre o processo de avaliação no ensino superior brasileiro, em nível de graduação e pós-graduação, além de expor tendências e possíveis mudanças para os próximos anos.

\section{RESULTADOS}

Considerando o objetivo deste artigo no qual consiste em apresentar características e tendências do processo de avaliação no sistema nacional de educação com ênfase nos níveis de graduação e pós-graduação, verifica-se boa parte alcançada na própria etapa de confecção da fundamentação teórica, com informações sobre o que é avaliação, como ocorre a auto avaliação, a importância de se avaliar a coordenação de curso no que diz respeito a avaliação de curso, bem como a relevância da participação de todos os envolvidos no processo de avaliação.

Com ênfase na graduação, além do retrato realizado na fundamentação teórica sobre o contexto histórico e os agentes envolvidos no processo de avaliação, importante destacar sobre o Sistema Nacional de Avaliação da Educação Superior (SINAES), instituído pela Lei n. 10.861/2004. Ressalta-se aqui o fluxograma do processo de avaliação in loco, conforme representado na figura 02 , que tem por objetivo identificar as condições de ensino oferecidas aos estudantes e assim garantir a qualidade mínima no ensino superior. 
Figura 02 - Fluxo do Processo de avaliação in loco do SINAES.

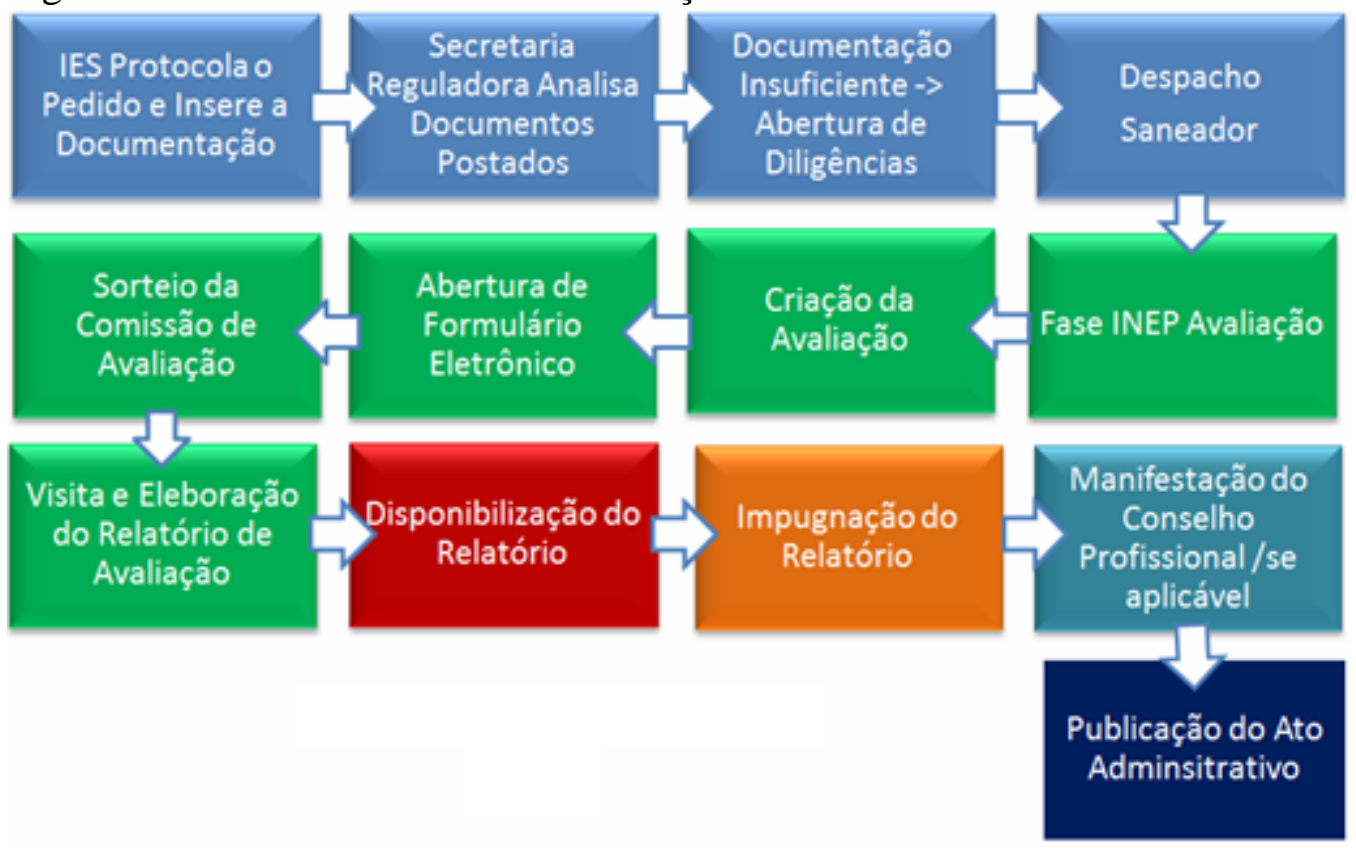

Fonte: Extraído de INEP (2015, p. 98).

$\mathrm{Na}$ fase inicial do processo, a IES protocola seu pedido no Sistema e-MEC, inserindo a documentação necessária. Para avaliação institucional, devem ser postados os documentos listados no art. 15 do Decreto n. 5.773/2006. Para a avaliação de curso, devem ser postados os documentos listados no art. 30 para o ato de autorização; art. 35 para reconhecimento de curso; e art. 41 para renovação de reconhecimento. Posteriormente a SERES analisa toda a documentação. Após análise, emite o despacho saneador, o qual poderá ser satisfatório, parcialmente satisfatório ou insatisfatório. Caso seja insatisfatório, o processo deverá ser arquivado e não terá fluxo para o Inep (INEP, 2015).

$\mathrm{Na}$ sequencia do processo, cabe evidenciar sobre a comissão de avaliação onde será composta por dois avaliadores para os atos regulatórios de cursos e três avaliadores para os atos regulatórios institucionais. Concluída a etapa da avaliação in loco, será disponibilizado no sistema o relatório para manifestação da IES e da SERES, sendo possível, no caso de não concordância, impugná-lo. Se isto não ocorrer o conceito emitido pelos avaliadores será considerado como referencial para o ato normativo (INEP, 2015).

Ocorrendo a impugnação, o processo será submetido à CTAA, que julgará a pertinência do recurso. Caso o mesmo seja acatado, decidir-se-á sobre os seguintes pontos: Manutenção do parecer da comissão; reforma do parecer com alteração de conceito; anulação do parecer e avaliação, implicando em nova visita. Seguindo o fluxo do processo avaliativo, os processos são encaminhados à SERES para emissão do Ato Autorizativo (INEP, 2015).

No que tange a pós-graduação, a IES deverá abrir processo solicitando o credenciamento e autorização de seus cursos. Posteriormente, deverá solicitar recredenciamento, reconhecimento e renovação de reconhecimento destes cursos. Dessa maneira, observa-se que o sistema de avaliação pode ser dividido em duas vertentes, ou seja, avaliação de novos entrantes no sistema de pós-graduação, figura 03 , e avaliação referente à permanência daqueles que já estavam, figura 04.

Outro ponto relevante é a definição dos conceitos dos programas, oriundos das avaliações, cuja variação numérica é de 1 a 7 . Notas 1 e 2 são consideradas insuficientes e provocam o descredenciamento do curso. Nota 3 corresponde a desempenho médio, que apresenta padrões mínimos de qualidade. Notas 4 e 5 significam um desempenho entre bom e muito bom, sendo 5 a nota máxima para programas que possuem apenas curso de mestrado. 
Notas 6 e 7 indicam desempenho equivalente a padrões internacionais de excelência. Quanto a classificação da produção científica, é realizada com a seguinte escala: A1, o mais elevado; A2; B1; B2; B3; B4; B5; C - com peso zero.

Figura 03 - Entrada no SNPG: Avaliação de Propostas de Cursos Novos.

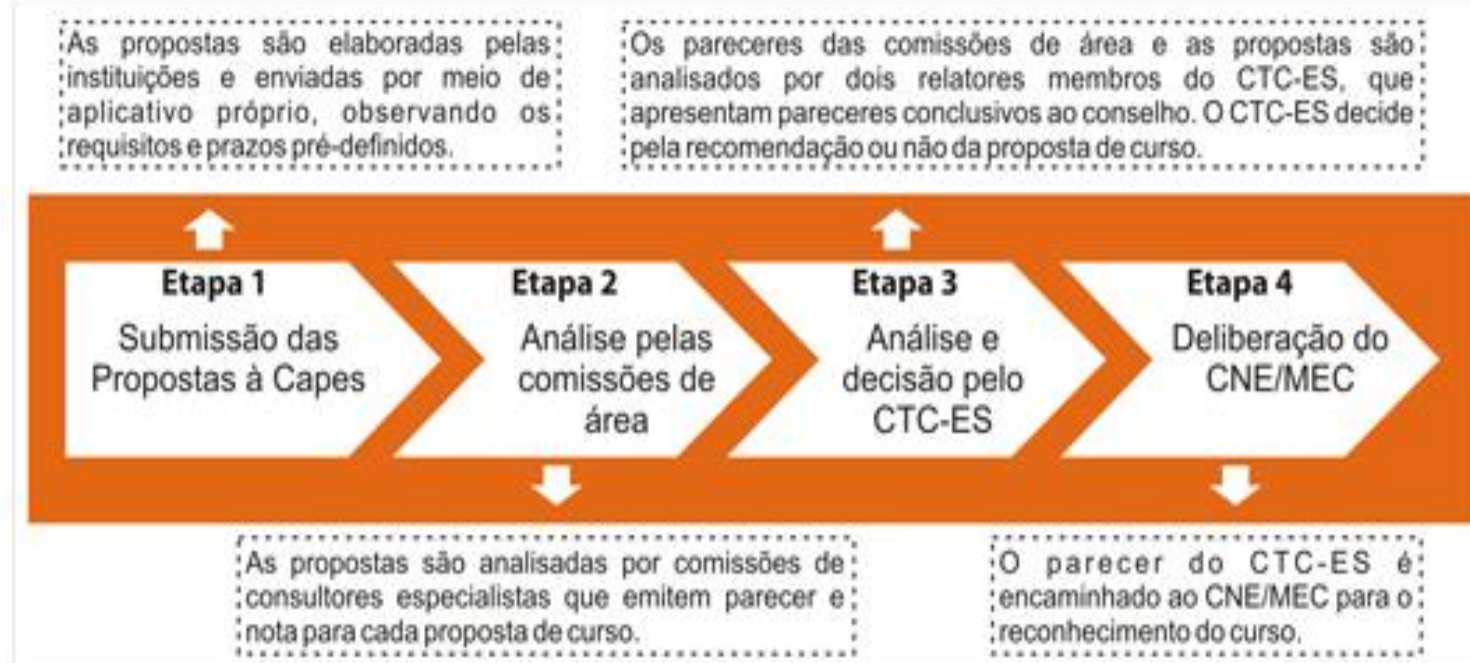

Fonte: Portal CAPES. Entrada no SNPG: propostas de cursos novos (BRASIL, 2014).

Figura 04 - Permanência no SNPG: Avaliação Trienal.

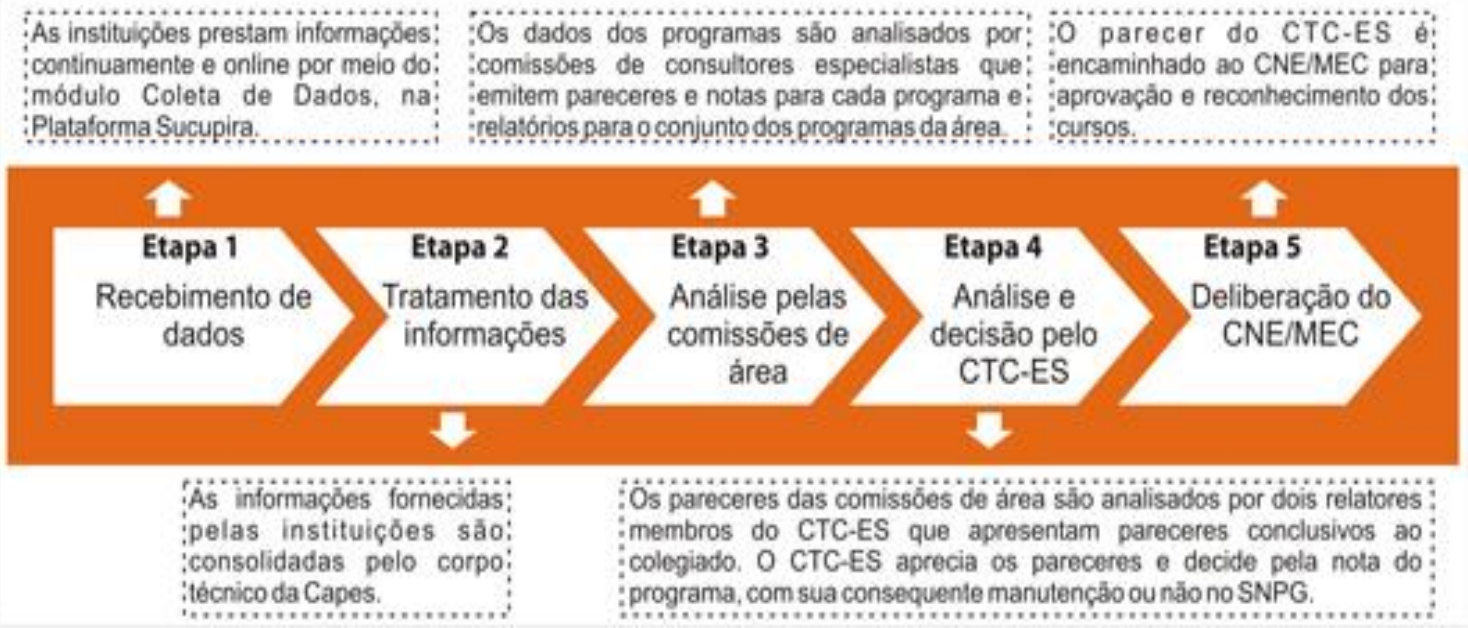

Fonte: Portal CAPES. Permanência no SNPG: avaliação (BRASIL, 2014)

Por fim, diante dos desafios e questionamentos ao sistema atual de avaliação algumas tendências se formulam com perspectivas de aperfeiçoar o processo atual e torná-lo mais eficiente e eficaz. Nesse sentido, o PNPG traz recomendações para o ciclo que finaliza em 2020 objetivando a eliminação de fragilidades. Destacam-se algumas destas recomendações no quadro 02 (BRASIL, 2010). 
Quadro 02 - Recomendações do PNPG ciclo 2011-2020 ao Processo de Avaliação.

\begin{tabular}{|c|c|}
\hline Objetivo & Descrição \\
\hline $\begin{array}{l}\text { Reduzir periodicidade de } \\
\text { Avaliação }\end{array}$ & $\begin{array}{l}\text { Alongamento da periodicidade da avaliação e aplicação em diferentes épocas, } \\
\text { mormente aos cursos com conceito } 6 \text { e } 7 \text {, que poderão concentrar suas forças na } \\
\text { produção de conhecimento novo, inovador, num período de } 5 \text { ou mais anos, sem o } \\
\text { risco de rebaixamento ou punição. Além disso, para os demais programas, a } \\
\text { execução de avaliações menos alongadas e acompanhamentos amiudados, com } \\
\text { vistas ao seu monitoramento e assim contribuindo para a manutenção da qualidade } \\
\text { vigente, melhoria da mesma e evolução de conceito. }\end{array}$ \\
\hline $\begin{array}{l}\text { Implementar novos } \\
\text { crivos de qualidade }\end{array}$ & $\begin{array}{l}\text { Adoção de crivos de qualidade, como no sistema inglês, onde os professores e } \\
\text { pesquisadores escolhem suas quatro ou cinco melhores produções do período e as } \\
\text { submetem ao escrutínio dos avaliadores. }\end{array}$ \\
\hline $\begin{array}{l}\text { Incorporar novos } \\
\text { parâmetros de } \\
\text { comparação adaptados a } \\
\text { realidade nacional }\end{array}$ & $\begin{array}{l}\text { Incorporação de parâmetros no processo de avaliação que não sejam } \\
\text { exclusivamente os das áreas básicas e acadêmicas, a fim de contribuir na } \\
\text { formação de pós-graduados voltados para atividades extra acadêmicas; } \\
\text { Incluir na avaliação dos programas de natureza aplicada parâmetros que } \\
\text { incentivem a formação de parcerias com o setor extra acadêmico, visando à } \\
\text { geração de tecnologia e à formação de profissionais voltados para o setor } \\
\text { empresarial. }\end{array}$ \\
\hline $\begin{array}{l}\text { Introduzir parâmetros } \\
\text { internacionais de } \\
\text { comparação }\end{array}$ & $\begin{array}{l}\text { Adotar como um dos parâmetros de avaliação a comparação com programas } \\
\text { internacionais considerados de referência, sem qualquer cota previamente } \\
\text { estabelecida para a classificação de programas nos níveis de excelência. Com } \\
\text { enfoque aos programas de conceito } 5,6 \text { e } 7 \text {. }\end{array}$ \\
\hline $\begin{array}{l}\text { Inserir parceiros } \\
\text { internacionais no } \\
\text { processo avaliativo }\end{array}$ & $\begin{array}{l}\text { Contratação de consultores internacionais tanto para monitorar o sistema de } \\
\text { avaliação da CAPES, tomando a agência como objeto ou alvo, quanto para } \\
\text { acompanhar a avaliação dos cursos } 6 \text { e } 7 \text {, assessorando o Conselho Técnico } \\
\text { Científico (CTC) e os Comitês. }\end{array}$ \\
\hline $\begin{array}{l}\text { siderar critérios } \\
\text { liação que } \\
\text { m assimetrias }\end{array}$ & $\begin{array}{l}\text { Não considerar critérios que contemplem assimetrias no processo de avaliação de } \\
\text { programas, especialmente no caso de mestrados localizados em regiões em estado } \\
\text { de desenvolvimento ainda incipiente. }\end{array}$ \\
\hline
\end{tabular}

Fonte: Elaborado pelo autor com base no PNPG 2011-2020 (BRASIL, 2010).

Em complemento as informações do PNPG, verifica-se que diversas ações já foram executadas, por exemplo, com a avaliação quadrienal prevista para esse ano; uso de dados sobre os egressos dos cursos de mestrado e doutorado para medir a inserção social, fato não realizado nas edições anteriores; uso da Plataforma Sucupira, implementada em 2014; ficha de avaliação própria aos mestrados profissionais voltados à formação de professores da educação básica (BRASIL, 2017).

Com relação às ações práticas a serem executadas, recentemente o MEC anunciou a alteração da forma de avaliação do ensino superior com a introdução de novos indicadores, citando o Índice de Desempenho dos Cursos (IDC) e o Índice de Desempenho Institucional (IDI) em substituição dos indicadores atuais CPC e IGC, respectivamente. Além disso, também será utilizado o Exame Nacional do Ensino Médio (ENEM) como parâmetro na avaliação e uma ação de forma mais abrupta é a alteração do sistema de avaliação vigente (ESTADÃO, 2016).

Corrobora com essa conjectura a ABMES (2017) ao ilustrar, conforme relatado pelo atual Coordenador Geral de Controle de Qualidade da Educação Superior do INEP, Renato Augusto dos Santos, que apesar da importância dos indicadores resultantes do ENADE, eles não retratam as condições concretas dos processos formativos e estruturas das IES. O conceito ENADE, o CPC e o IGC expressam valores relativos, e não absolutos, demandando a avaliação in loco. Além disso, os indicadores não são comparáveis entre suas edições e necessitam de ajustes para fins de regulação, supervisão e financiamento.

Outro ponto evidenciado pela ABMES (2017), segundo declarações do atual Diretor de Avaliação da Educação Superior do INEP, Rui Barbosa Brito Junior, refere-se à ocorrência de estudos para aprimoramento dos processos avaliativos. Também, planejam a implantação 
de um novo modelo de organização no ENADE 2018. Entre as mudanças previstas, estão a proposta de resultados do exame com perfil socioeconômico dos estudantes e a possibilidade da aplicação do ENADE em formato eletrônico, com vistas ao desenvolvimento de um sistema que permita a aplicação do exame de maneira censitária anualmente.

É possível vislumbrar a ocorrência de mais mudanças nos processos avaliativos da CAPES, decorrente da oferta de cursos na modalidade Doutorado Profissional, instituída na Portaria n. 389 de 23 de março de 2017, o que ensejará alterações no sistema atual para se adaptar a esta nova opção a ser oferecida pelas IES. Ressalta-se que a CAPES foi incumbida pelo MEC para regulamentar e disciplinar a oferta, avaliação e o acompanhamento dos programas de mestrado e doutorado profissional, ações que estão em desenvolvimento e em processo de consolidação.

\section{CONCLUSÃO}

Observa-se que apesar de jovem, o sistema de avaliação brasileiro pode ser considerado robusto, bem estruturado e de grande relevância para manutenção da qualidade do Ensino Superior. Centralizado sob a esfera governamental, conta com distintos agentes envolvidos para desenvolvimento das etapas do processo de avaliação, tanto em nível de graduação, quanto em nível de pós-graduação.

Na graduação, sua pertinência consiste em garantir a qualidade da educação superior, por meio das ações desenvolvidas frente à avaliação das instituições e de cursos. Tal fato ocorre em virtude do fornecimento de informações que possibilitam a regulação e supervisão da educação superior, compreendendo o credenciamento e a renovação de credenciamento de IES, a autorização, o reconhecimento e a renovação de reconhecimento de cursos de graduação. Consequentemente, IES e cursos que não atendem padrões mínimos de qualidade são "retirados" do sistema nacional de educação superior até sua devida readequação.

$\mathrm{Na}$ pós-graduação, torna-se ainda mais acentuada a relevância do processo de avaliação. Em síntese, a avaliação da pós-graduação stricto sensu é o instrumento fundamental do SNPG. Os resultados da avaliação têm usos diversos, mormente aos estudantes para se basearem nas notas e assim ampliar os parâmetros de decisão na escolha de seus futuros cursos; para ações de financiamento, dos quais as agências de fomento nacionais e internacionais orientam suas políticas de fomento segundo as notas atribuídas pela avaliação; identificação de assimetrias regionais; e de áreas estratégicas do conhecimento no SNPG, para orientar ações de indução na criação e expansão de programas de pós-graduação no território nacional.

Por fim, ressalta-se o perfil inovativo do sistema de avaliação nacional, com constante desenvolvimento de ações, a fim de se adaptar ao contexto atual frente às novas exigências socioeconômicas e impedir que a estrutura fique inerte, obsoleta vulnerável ao marasmo. Prova disso, são as ações já desenvolvidas, com fulcro no PNPG e as demais que estão a caminho.

\section{REFERÊNCIAS}

ALCADIPANI, R. Resistir ao produtivismo: uma ode à perturbação Acadêmica. Cadernos EBAPE.BR, v. 9, n. 4, p. 1174-1178, 2011.

ASSOCIAÇÃO BRASILEIRA DE MANTENEDORAS DE ENSINO SUPERIOR, ABMES. MEC Admite Limitações nos Indicadores de Qualidade do Ensino Superior. Abril, 2017. Disponível em: <http://abmes.org.br/noticias/detalhe/2068/mec-admite-limitacoes-nosindicadores-de-qualidade-do-ensino-superior->. Acesso em: 06/07/2017. 
BALBACHEVSKY, E. A pós-graduação no Brasil: novos desafios para uma política bemsucedida. In: BROCK. C.; SCHWARTZMAN, S. Os desafios da educação no Brasil. Rio de Janeiro: Nova Fronteira, 2005.

BARATA, R. C. B. Dez coisas que você deveria saber sobre o Qualis. RBPG Brasília, v. 13 n. 1 , jan/abr, 2016.

BISPO, Marcelo de Souza; COSTA, Francisco José da. Artigos como avaliação discente em disciplinas de pós-graduação: instrumento educativo ou subsistema de linha de montagem?. Cadernos EBAPE.BR, v. 14, n. 4, p. 1001-1010, out.-dez. 2016.

BRASIL. Ministério da Educação. Coordenação de Aperfeiçoamento de Pessoal de Nível Superior. Quadrienal 2017 apresenta mudanças na avaliação da pós-graduação. 2017. Disponível em: <http://www.capes.gov.br/sala-de-imprensa/noticias/8456-quadrienal-2017apresenta-mudancas-na-avaliacao-da-pos-graduacao>. Acesso em: 08/07/2017.

Ministério da Educação. Coordenação de Aperfeiçoamento de Pessoal de Nível Superior. Documento de Área: Administração pública e de Empresas, Ciências Contábeis e Turismo. 2016.

Ministério da Educação. Coordenação de Aperfeiçoamento de Pessoal de Nível Superior. Sobre a avaliação. 2014.

Ministério da Educação. Coordenação de Aperfeiçoamento de Pessoal de Nível Superior. Plano Nacional de Pós-Graduação - PNPG 2011-2020. Brasília, DF: CAPES, v.1. 309 p., 2010.

Ministério da Educação. Coordenação de Aperfeiçoamento de Pessoal de Nível Superior. História e missão. 2008. Atualizado em 01/03/2017. Disponível em: <http://www.capes.gov.br/historia-e-missao>. Acesso em: 01/06/2017.

Lei n. 10.861, de 14 de abril de 2004: Institui o Sistema Nacional de Avaliação da Educação Superior - SINAES e dá outras providências. 2004.

CRESPI, T. B.; PREUSLER, T. S.; LUNA, N. A.; FERREIRA, M. P.. Novo Qualis: Impacto na Avaliação da Produção Intelectual dos Pesquisadores em Administração. Revista de Ciências da Administração. v. 19, n. 47, p. 131-147, abril 2017.

CURY, Carlos Roberto Jamil. Graduação/pós-graduação: a busca de uma relação virtuosa. Educ. Soc. [online]. v. 25, n. 88, p.777-793. 2004.

DIAS, Ana Maria Iori.; KETZER, Solange Medina (Org.) . Memória do ForGRAD: 20 anos do Fórum Nacional de Pró-Reitores de Graduação das Universidades Brasileiras: Unidade na Diversidade. 01 ed. Porto Alegre: Edipucrs. v.1, 327 p., 2007.

DINALLI, Aparecida; ZAMBELLO, Aline Vanessa. Desafios da Avaliação na Educação Superior no Brasil. Revista de Direito Brasileira. São Paulo, SP. v. 16, n. 7, p. 363-385, Jan./Abr. 2017. 
ESTADÃO. Ministério altera a forma de avaliação do ensino superior. Abril, 2016. Disponível em: <http://educacao.estadao.com.br/noticias/geral,mec-altera-forma-deavaliacao-do-ensino-superior,10000032562>. Acesso em: 06/07/2017.

HORTA, J. S. B. Prefácio. In: BIANCHETTI, L.; MACHADO, A. N. M. (Org.). A bússola do escrever: desafios e estratégias de teses e dissertações. São Paulo: Cortez; Florianópolis: UFSC, 2002.

INEP. Portal Institucional: educação superior - Inep altera forma de divulgação dos Indicadores de Qualidade da Educação Superior referentes a 2016. Brasília/DF. 26/06/2017. Disponível em: <http://portal.inep.gov.br/artigo//asset_publisher/B4AQV9zFY7Bv/content/id/812641>. Acesso em: 04/07/2017.

Avaliação In Loco: Referenciais no âmbito do SINAES. INEP/MEC: Brasília/DF. v. 5,295 p., 2015.

KNOBEL, Marcelo; VERHINE, Robert. Brazil's For-Profit Higher Education Dilemma. International Higher Education, Chestnut Hill, Massachusetts. Spring, n. 89, p. 23-24, 2017.

KUENZER, Acacia Zeneida; MORAES, Maria Célia Marcondes de. Temas e Tramas na PósGraduação em Educação. Educação \& Sociedade, v. 26, n. 93, set.-dez., p. 1341-1362, 2005.

LAVOR, J. F. de; ANDRIOLA, W. B.; LIMA, A. S.. Avaliando o Impacto da Qualidade da Gestão Acadêmica no Desempenho dos Cursos de Graduação. Um Estudo em Universidade Pública Brasileira. Rev. Iberoamericana de Evaluación Educativa. v. 8, n. 2, p. 233-254, 2015.

LIEVORE, Caroline; PICININ, Claudia Tania; PILATTI, Luiz Alberto. As áreas do conhecimento na pós-graduação stricto sensu brasileira: crescimento longitudinal entre 1995 e 2014. Ensaio: Avaliação e Políticas Públicas em Educação, v. 25, n. 94. p. 207-237, 2017.

PASCUCI, L.; MEYER JR., V.; MAGIONI, B.; SENA, R.; Managerialism na gestão universitária: Implicações do planejamento estratégico segundo a percepção de gestores de uma Universidade pública. Revista Gestão Universitária na América Latina - GUAL, Florianópolis, v. 9, n. 1. p. 37-59, jan., 2016.

PINTO, R. S.; MELLO, S. P. T. de; MELO, P. A.. Meta-avaliação: uma década do Processo de Avaliação Institucional do SINAES. Avaliação, Campinas. v. 21, n. 1, p. 89-107, 2016.

SCORSOLINE, Ailton Bueno. Controle da qualidade da educação superior brasileira: modelos em transição. Laplage em Revista. v. 1. n.1, p. 73-83, 2015.

STEINER, J. E.. Qualidade e diversidade institucional na pós-graduação brasileira. Estudos Avançados v. 19, n. 54, p. 341-365, 2005.

VERGARA, S. C.. Projetos e relatórios de pesquisa em administração. 14. Ed. São Paulo (SP): Atlas, 2013.94 p. 